\title{
Photodegradation of 1-(2-Chlorobenzoyl)-3-(4-chlorophenyl) Urea in Different Media and Toxicity of Its Reaction Products
}

\author{
Liu Guoguang, ${ }^{\dagger}$ J iang Xiangning, and Xu Xiaobai* \\ Research Center for Eco-Environmental Sciences, Chinese Academy of Sciences, \\ Beijing 100085, People's Republic of China
}

\begin{abstract}
The photodegradation of 1-(2-chlorobenzoyl)-3-(4-chlorophenyl) urea in simulated air, methanol, dioxane, hexane, and water, with a xenon lamp as light source, was studied. The rate constants and half-lives of this compound in various media under nitrogen or oxygen were determined. The photoreaction products were analyzed with HPLC-UV, GC-MS, and direct probe MS and found to have some differences in different cases. With ${ }^{32} \mathrm{P}$ postl abeling DNA adduct formation experiments, one of the main products, 2-chorobenzamide, was found to be able to form a DNA adduct.
\end{abstract}

Keywords: 1-(2-Chl orobenzoyl)-3-(4-chlorophenyl) urea; photodegradation; 2-chlorobenzamide; DNA adducts

\section{INTRODUCTION}

1-(2-Chl orobenzoyl)-3-(4-chlorophenyl) urea (CCU), also named benzamide [2-chloro-(((4-chlorophenyl)amino)carbonyl], is a new chemical of phenylurea insecticides, after DFB and PH6038. It has been synthesized and commercialized in China since the early 1980s and is now used widely in forestry and agriculture. Some physi cochemical properties of CCU and also its IR, UV, and MS spectra had been reported in one of our previous papers (1). Its melting point was determined as $196-198{ }^{\circ} \mathrm{C}$, and thermogravimetric analysis indicates that it is stable below $230^{\circ} \mathrm{C}$. In this paper, our results of the kinetics and mechanisms of the photodegradation of CCU in simulated air, in organic solvents, and in water will be reported and discussed. These results can serve as supplemental data for the safety evaluation of the environmental effects of CCU.

\section{MATERIALS AND METHODS}

2.1. Materials. CCU was produced by Tonghua Factory of Insecticides (J inlin Province), and after recrystall ization three times with toluene, its purity was 98\%. Silica gel (100-200 mesh) was from Shanghai Wusi Chemical Factory and was pretreated with methanol and dichloromethane before use (1). All solvents, methanol, 1,4-dioxane, and dichloromethane, were from Beijing Chemical F actory and redistilled before use. Four standard compounds, 4-chloroaniline, 4-chlorophenyl urea, 2-chlorobenzamide, and 2-chlorobenzoic acid, were supplied by Wuhan Institute of Hydrobiology, Chinese Academy of Sciences. Chlorobenzene was the standard reagent from the U.S. EPA. 2-Chloro-N-(4-chlorophenyl) benzamide was from an HPLC fraction and identified with MS.

2.2. Apparatus. A Shimadzu LC-5A HPLC was equipped with an SPD-1 UV detector, the GC-MS was aF innigan MAT4510, and a Branson B-32 ultrasonicater was used. As the radiating spectrum of xenon lamp continues from UV to near-

* Author to whom correspondence should be addressed.

† Present address: College of Chemistry and Environmental Science, Henan Normal University, Xinxiang 453002, People's Republic of China.
$I R$, which is similar to sunlight $(2,3)$, an $X Q-200 \mathrm{~W}$ xenon lamp with XQ150-500 DC power from Shanghai Lightening Device Factory was taken as light source in all of our experiment. A 75L-III accumulation emission meter from Tianjin Third Analytical Instrument Factory was used to measure the light intensity in the reactor. The photoreaction instruments were described elsewhere (4-7), with quartz reactors made in our center.

2.3. Procedures. 2.3.1. Photoreaction Experiment. 2.3.1.1. Under Simulated Atmospheric Condition. CCU was coated on silica gel (4). Approximately $1 \mathrm{~g}$ of the silica gel sample was introduced into the fluidized bed quartz reaction chamber and suspended in oxygen or nitrogen, with the flow rate controlled at $100 \mathrm{~mL} / \mathrm{min}$. The xenon lamp was then turned on, and the light intensity in the reactor was measured as $2.60 \mathrm{~J} / \mathrm{cm}^{2} \cdot \mathrm{min}$. During irradiation, sample aliquots of $\sim 100 \mathrm{mg}$ each were taken out at set time intervals and then weighed and extracted with dioxane. Thus, the variation of concentration of CCU on silica gel was measured with HPLC. After $120 \mathrm{~h}$ of exposure, the sample was taken from the reaction chamber and extracted with methanol. The extract solution was concentrated to $1 \mathrm{~mL}$, and the reaction products were identified with HPLC-UV, GCMS, and direct probe MS.

2.3.1.2. In Organic Solvents. Fifty milliliters of methanol, dioxane, or hexane solution at $\sim 50 \mathrm{ppm}$ of CCU was added into the quartz cylindrical reaction chamber $\left(25 \pm 2^{\circ} \mathrm{C}\right)$, and nitrogen or oxygen was passed through the solution at $40 \mathrm{~mL} /$ min to keep the solution saturated. The variation of the CCU concentration with time of exposure under the xenon lamp, the light intensity in the reactor measured as $2.10 \mathrm{~J} / \mathrm{cm}^{2} \cdot \mathrm{min}$, was studied by taking samples at set time intervals and analyzing with HPLC. After $15 \mathrm{~h}$, the solution was transferred to the K-D concentrater and concentrated to $1 \mathrm{~mL}$. The products were then identified with HPLC-UV and GC-MS.

2.3.1.3. In Water Phase Five hundred milliliters of water solution with CCU at $\sim 5 \mathrm{ppm}$ was added into a cool photoreactor, and oxygen or nitrogen was passed through the solution at $400 \mathrm{~mL} / \mathrm{min}$. At every fixed time interval, $5 \mathrm{~mL}$ of solution was taken out from the reactor and extracted with dichloromethane. After concentration, the extract was dissolved in $0.5 \mathrm{~mL}$ of methanol and analyzed with HPLC (7). After $30 \mathrm{~h}$ of exposure, all of the solution was taken out and extracted, the extract after concentration was dissolved in 0.1 $\mathrm{mL}$ of methanol, and the photoproducts were identified with HPLC-UV and GC-MS.

Meanwhile, dark experiments under the same conditions and with the same procedures as mentioned above for the 
Table 1. Net Photoreaction Kinetics Equations

\begin{tabular}{|c|c|c|c|c|}
\hline medium & gas & equation & $\mathrm{R}$ & $\begin{array}{l}\text { half- } \\
\text { life (h) }\end{array}$ \\
\hline $\begin{array}{l}\text { simulated } \\
\text { atmosphere }\end{array}$ & $\begin{array}{l}\mathrm{O}_{2} \\
\mathrm{~N}_{2}\end{array}$ & $\begin{array}{l}1 / c=0.295+0.00445 t \\
\ln 1 / c=-1.27+0.00703 t\end{array}$ & $\begin{array}{l}0.983 \\
0.989\end{array}$ & $\begin{array}{l}62.7 \\
98.6\end{array}$ \\
\hline methanol & $\begin{array}{l}\mathrm{O}_{2} \\
\mathrm{~N}_{2}\end{array}$ & $\begin{array}{l}\ln 1 / c=-3.99+0.129 t \\
\ln 1 / c=-3.98+0.118 t\end{array}$ & $\begin{array}{l}0.998 \\
0.997\end{array}$ & $\begin{array}{l}5.37 \\
5.87\end{array}$ \\
\hline 1,4-dioxane & $\begin{array}{l}\mathrm{O}_{2} \\
\mathrm{~N}_{2}\end{array}$ & $\begin{array}{l}\ln 1 / c=-3.94+0.182 t \\
\ln 1 / c=-3.98+0.278 t\end{array}$ & $\begin{array}{l}0.999 \\
0.997\end{array}$ & $\begin{array}{l}3.81 \\
2.49\end{array}$ \\
\hline hexane & $\begin{array}{l}\mathrm{O}_{2} \\
\mathrm{~N}_{2}\end{array}$ & $\begin{array}{l}\ln 1 / c=-2.86+1.70 t \\
\ln 1 / c=-2.87+1.69 t\end{array}$ & $\begin{array}{l}0.999 \\
0.997\end{array}$ & $\begin{array}{l}0.41 \\
0.41\end{array}$ \\
\hline water & $\begin{array}{l}\mathrm{O}_{2} \\
\mathrm{~N}_{2}\end{array}$ & $\begin{array}{l}\text { In } c / c_{0}=-0.0227 t \\
\text { In } c / c_{0}=-0.0125 t\end{array}$ & & $\begin{array}{l}31 \\
55\end{array}$ \\
\hline
\end{tabular}

different cases were carried out in parallel for comparison without the application of the xenon lamp.

2.3.2. DNA Adduct Formation Experiment. Both the mixture of products and 2-chlorobenzamide (one of the main products of $\mathrm{CCU}$ ) were tested with ${ }^{32} \mathrm{P}$-postlabeling for DNA adduct formation, following the procedure described (8).

2.4. HPLC Analysis. HPLC was used to determine the concentration of CCU during experiments. The chromatographic conditions used were as follows: HPLC column, 250 $\times 4.6 \mathrm{~mm}$ Zorbax C8; mobile phase, $\mathrm{CH}_{3} \mathrm{OH} / \mathrm{H}_{2} \mathrm{O}(90: 10 \mathrm{v} / \mathrm{v})$, at a flow rate of $1 \mathrm{~mL} / \mathrm{min}$; detector, UV-254 $\mathrm{nm}$.

2.5. Identification of the Reaction Products. 2.5.1. Separation and Identification by HPLC. The chromatographic conditions used were as follows: HPLC col umn, $250 \times 4.6 \mathrm{~mm}$ Zorbax C8; mobile phase, $\mathrm{CH}_{3} \mathrm{OH} / \mathrm{H}_{2} \mathrm{O}(70: 30 \mathrm{v} / \mathrm{v})$, at a flow rate of $0.4 \mathrm{~mL} / \mathrm{min}$; detector, UV-254 nm.

2.5.2 I dentification with GC-MS. GC/MS conditions were as follows: SE 54 capillary fused silica col umn of $30 \mathrm{~m} \times$ i.d., 0.22 $\mathrm{mm}$; column temperature programmed from 60 to $220^{\circ} \mathrm{C}$ at 4 ${ }^{\circ} \mathrm{C} / \mathrm{min}$ and then from 220 to $300^{\circ} \mathrm{C}$ at $10^{\circ} \mathrm{C} / \mathrm{min}$; MS system with electron impact mode at $70 \mathrm{eV}$, ion current at $270 \mu \mathrm{A}$, mass scan range from 33 to $500 \mathrm{amu}$, with scan rate at 30 amu/min and ionization temperature at $300^{\circ} \mathrm{C}$.

2.5.3. Identification with Direct Probe MS. The reaction products were separately collected with HPLC and then identified with direct probe MS. The MS condition was an ionization temperature gradient from 80 to $300{ }^{\circ} \mathrm{C}$ at $30{ }^{\circ} \mathrm{C} /$ $\min$.

\section{RESULTS AND DISCUSSION}

3.1. Photodegradation Kinetics. The apparent photodegradation and the dark reaction of CCU under simulated atmospheric condition, in organic solvents and water phase, and under oxygen or nitrogen were studied in parallel. The results showed that the dark reactions are unimportant under simulated atmospheric condition or in organic solvents, whereas the dark reaction in water is important. These results imply that CCU is stable in the particle-bound form or in organic solvents under dark conditions, but hydrolysis occurs in water phase no matter whether the light exists or not.

The photodegradation kinetics are almost all of first order, except that the photoreaction under simulated atmospheric condition with oxygen as saturating gas is of second order. The net photodegradation kinetics equations are listed in Table 1.

From Table 1, it can be seen that photoreactions are faster in simulated atmosphere, 1,4-dioxane, or water when oxygen is used as the saturating gas instead of nitrogen. However, there are no differences in methanol and hexane when either of these two saturating gases is used. The reaction rates for different media follow the order hexane $>$ dioxane $>$ methanol $>$ water.
3.2. Photodegradation Products. The photodegradation products of $\mathrm{CCU}$ in various media identified with HPLC-UV, GC-MS, and direct probe MS are listed in Table 2.

2-Chlorobenzamide is al ways the main photoproduct in every case; the relative amounts of 4-chlorophenyl isocyanate and its derivative N-(4-chlorophenyl) methylcarbamate or N-phenyl methyl carbamate are high or medium in different media.

3.3. Mechanism of Photodegradation. The photodegradation rates of CCU in different media are ordered as follows: in hexane > in dioxane $>$ in methanol >in water, with the increasing polarity of these solvent media. This means that the photodegradation of CCU probably or most likely occurs through free radical pathways. On the basis of the chemical identities of the products, the mechanism of photodegradation is suggested as follows:

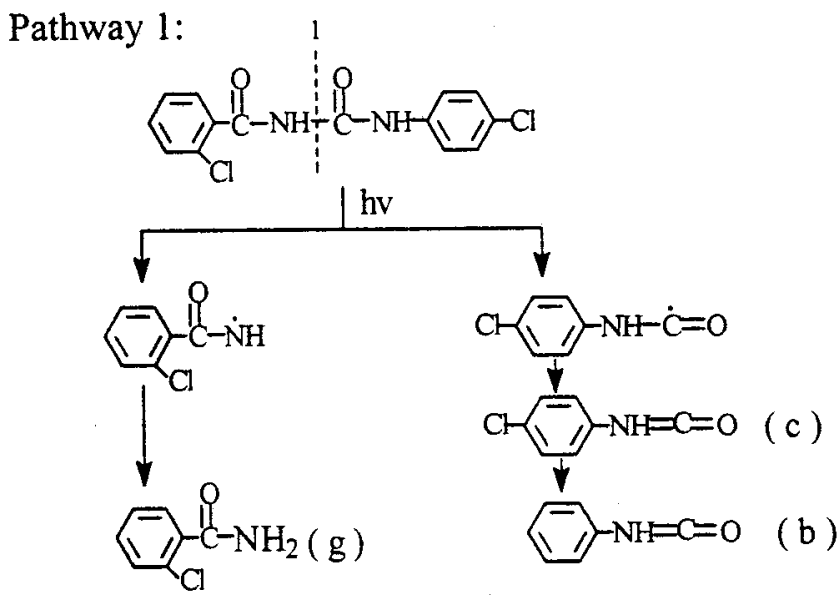

Pathway 2:

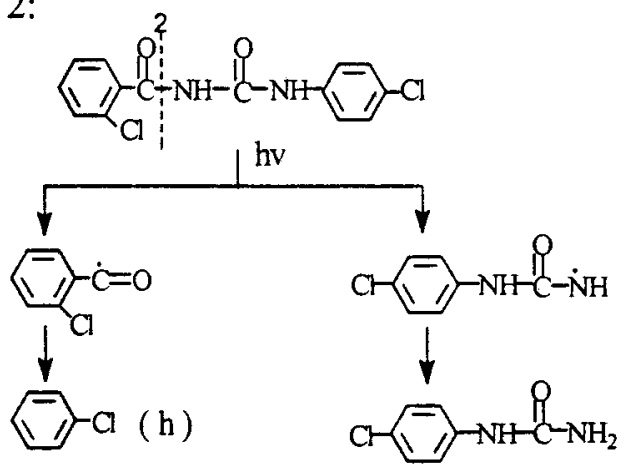

Pathway 3:

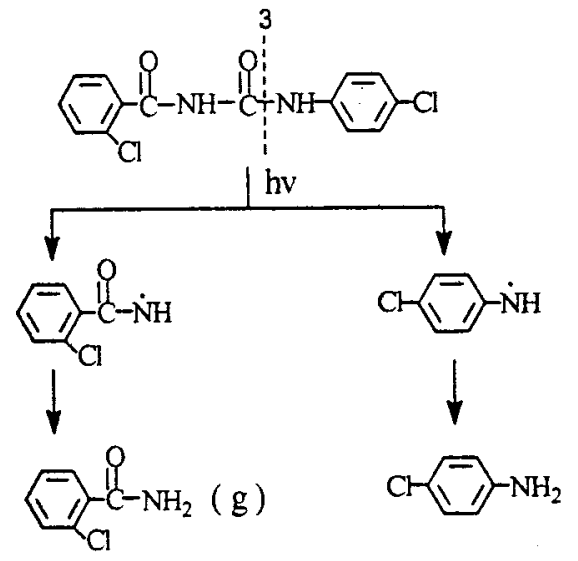


Table 2. Photodegradation Products

\begin{tabular}{|c|c|c|c|c|c|c|c|c|c|c|c|}
\hline \multirow[b]{2}{*}{ Number } & \multirow{2}{*}{ Structure formula } & \multirow{2}{*}{$\begin{array}{l}\text { Identified by } \\
\qquad * *\end{array}$} & \multicolumn{2}{|c|}{$\mathrm{RT}(\mathrm{min})$} & \multirow{2}{*}{ Mol.wt } & \multirow{2}{*}{$\begin{array}{c}\text { Main MS } \\
\text { fragm }\end{array}$} & \multicolumn{5}{|c|}{ Relative content in various media * } \\
\hline & & & HPLC & GC-MS & & & $\begin{array}{c}\text { Simulated } \\
\text { atmosphere }\end{array}$ & methanol & dioxane & hexane & water \\
\hline $\mathrm{a}$ & & 1 & 5.0 & & 156 & - & & & & & $\mathrm{H}$ \\
\hline $\mathrm{b}$ & $c=0$ & 2 & & 7.7 & 119 & $119\left(\mathrm{M}^{+}\right), 91$ & & $\mathrm{~L}$ & & & \\
\hline c & $\mathrm{C}=\mathrm{O}$ & 2 & & 13.8 & 153 & $155,153\left(\mathrm{M}^{+}\right), 125,90$ & M & $\mathrm{L}$ & $\mathrm{H}$ & & $\mathrm{H}$ \\
\hline d & & 1,2 & 11.0 & 18.4 & 127 & $129,127\left(\mathrm{M}^{+}\right), 92$ & M & & & & $\mathrm{L}$ \\
\hline e & 勿 & 2 & & 20.8 & 170 & $172,170\left(\mathrm{M}^{+}\right), 139,111$ & $\mathrm{~L}$ & & & & \\
\hline $\mathrm{f}$ & 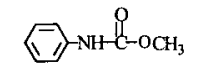 & 2 & & 21.6 & 151 & $151\left(\mathrm{M}^{+}\right), 119,92,77$ & & $\mathrm{H}$ & & & \\
\hline $\mathrm{g}$ & & 1,2 & 7.5 & 26.2 & 155 & $157,155\left(\mathrm{M}^{+}\right), 139,111$ & H & $\mathrm{H}$ & $\mathrm{H}$ & H & $\mathrm{H}$ \\
\hline $\mathrm{h}$ & & 1 & 9.3 & & 112 & - & & $\mathrm{L}$ & & & \\
\hline $\mathrm{i}$ & 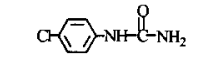 & 1,3 & 9.8 & & 170 & $172,170\left(M^{+}\right), 127$ & M & L & $\mathrm{H}$ & & $\mathrm{H}$ \\
\hline $\mathrm{j}$ & ar $(-7) \mathrm{NH}_{-1}^{0}-\mathrm{OCH}_{3}$ & 2 & & 28.4 & 185 & $187,185\left(\mathrm{M}^{+}\right), 153,126$ & & M & & $\mathbf{H}$ & \\
\hline $\mathrm{k}$ & (O) ${ }_{\mathrm{Cl}}^{\mathrm{C}-\mathrm{NH}}-\mathrm{O} \longrightarrow \mathrm{Cl}$ & 2,3 & 18.8 & 46.4 & 265 & $267,265\left(\mathrm{M}^{+}\right), 139,111$ & $\mathrm{~L}$ & $\mathrm{~L}$ & & & $\mathrm{~L}$ \\
\hline
\end{tabular}

* H-high, M-medium, L-low. ${ }^{* *} \mathrm{l}=\mathrm{HPLC}-\mathrm{UV}$, the retention time in HPLC and the UV-spectrum of the product was as the same as that of standard compound. $2=\mathrm{GC}-\mathrm{MS}$ the products were identified with GC-MS. $3=$ Direct Probe MS the products were separately collected with HPLC, and then identified with direct probe MS

Table 3. Relative Adductive Rates of DNA Adducts

\begin{tabular}{ccccc}
\hline chemical & spot 1 & spot 2 & spot 3'/3 & spot 4 \\
\hline products mixture & & $7.1 \times 10^{-9} \mathrm{RAL}^{\mathrm{a}}$ & $2.3 \times 10^{-8} \mathrm{RAL}$ & $8.0 \times 10^{-8} \mathrm{RAL}$ \\
CBA & $1.1 \times 10^{-8} \mathrm{RAL}$ & $4.1 \times 10^{-9} \mathrm{RAL}$ & $3.9 \times 10^{-9} \mathrm{RAL}$ & $3.0 \times 10^{-8} \mathrm{RAL}$
\end{tabular}

a $\mathrm{RAL}$, relative adduct labeling $=$ [radioactive count of adducted base $(\mathrm{cpm})$ - blank radioactive count (cpm)] $\div$ [radioactive count of normal DNA base $(\mathrm{cpm})+\sum$ radioactive count of adducted base (cpm)].

Some free radicals can react with each other to form some new products, such as

$\underbrace{}_{\mathrm{C}} \mathrm{C}=\mathrm{O}+\mathrm{C}-\overrightarrow{\mathrm{N} H} \longrightarrow \overrightarrow{\mathrm{C}}$

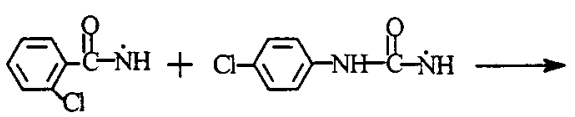

$$
{ }_{\mathrm{Cl}}^{\mathrm{O}} \mathrm{NH}-\mathrm{NH}_{2}(\mathrm{e})+\mathrm{Cr}-\mathrm{NH}_{2}
$$

Moreover, some products can further react with solvent molecules as follows:

In methanol:

$$
\begin{aligned}
& \text { C- }-\mathrm{N}=\mathrm{C}=\mathrm{O}+\mathrm{CH}_{3} \mathrm{OH} \longrightarrow \mathrm{Cr}-\mathrm{NH}+\stackrel{\mathrm{O}}{\mathrm{C}}-\mathrm{OCH}_{3}(\mathrm{j}) \\
& \leadsto-\mathrm{N}=\mathrm{C}=\mathrm{O}+\mathrm{CH}_{3} \mathrm{OH} \longrightarrow-\mathrm{NH}+\stackrel{\mathrm{O}}{-}-\mathrm{OCH}_{3}
\end{aligned}
$$

In water:<smiles>Cc1ccc(C(=O)O)c(Cl)c1</smiles>

According to Riley (9), the lengths of amide bonds 1 , 2 , and 3 in DFB are 1.410, 1.378, and $1.337 \AA$,

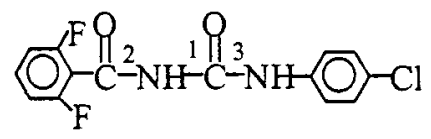

respectively. The stability sequence of these three bond is $1<2<3$. Considering the similar structures of $\mathrm{CCU}$ and DF B, we could infer that pathway 1 possibly is the easiest to take place, whereas pathway 2 or 3 is more difficult to take place. Thus, 2-chlorobenzamide, 4chlorophenyl isocyanate, isocyanatobenzene, and their derivatives should be the main products. This is consistent with the results of our experiments.

3.4. DNA Adducts. With the ${ }^{32} \mathrm{P}$ postlabeling test, both the product mixture of CCU and 2-chlorobenzamide (CBA), which is one of the main products, are found to be able to react with DNA to form similar adducts. The results can be seen from Figure 1 .

From Figure 1, three and four visible spots of DNA adducts with the mixture of degradation products and CBA, respectively, can be seen, and their relative adductive rates are shown in Table 3.

The results from $\mathrm{F}$ igure 1 and Table 3 show that CBA is the main dedicator for DNA adduct formation in the product mixture. 


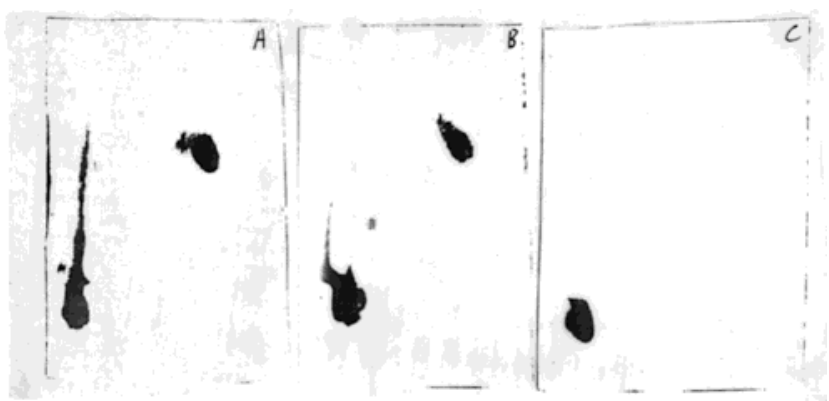

Figure 1. Autoradiograms of DNA adduct formation: (A) degradation products mixture of $\mathrm{CCU}-\mathrm{DNA}$ adducts; (B) CBA-DNA adducts; (C) blank DNA (calf thymus).

If one chemical can form adducts with DNA, and the injured DNA cannot be repaired, the chemical is a potential mutagen, carcinogen, or teratogen. Accordingly, CBA may be a potential carcinogen or mutagen, especially due to the fact that a positive result for CBA in the Ames test has been noted by Dr. Wang Dai of the Institute of Biochemistry, Chinese Academy of Sciences. It is now suggested that for the safety evaluation of pesticides, the properties of not only the pesticide but also its products should be considered. As CBA is one of the main degradation products of CCU, the safety of CCU to ecological systems or human health should be of great concern. F urther studies about CCU in the environment are being carried out in our laboratory $(10,11)$.

\section{ACKNOWLEDGMENT}

We appreciate the support from Professors Mo Hanhong (purified CCU), Liu Sufen, and Wang Dai.

\section{LITERATURE CITED}

(1) Liu, Guoguang; J in, Zuliang; Xu, Xiaobai. Preliminary study of the kinetics of photodecomposition of Benzamide, 2-chloro-N-(((4-chlorophenyl)amino)carbonyl) under simulated atmospheric conditions. Huanjing Kexue 1990, 11 (5), 12-15.

(2) Li, A. S. W.; Chignell, C. F. Spectroscopic studies of cutaneous photosensitizing agents $-X I$. Photolysis of chloropromazine metabolites: a spin-trapping study. Photochem. Photobiol. 1987, 45, 695-701.
(3) Niu, E.; Ghiggino, K. P.; Mau, A. W. H.; Sasse W. H. F. Fluorescence and photochemistry of dye sensitizers in Nafion membrane. J . Luminesecence 1988, 40-41, 563564.

(4) Liu, Guoguang; J in, Zuliang; Xu, Xiaobai Photoreaction of 1-(2-chlorobenzoyl)-3-(4-chlorophenyl) urea in simulated atmosphere. J . Environ. Sci. (China) 1992, 4 (4), $52-60$.

(5) Liu, Guoguang; J in, Zuliang; Xu, Xiaobai. Study on the photorection of 1-(2-chlorobenzoyl)-3-(4-chlorophenyl) urea in methanol. J . Environ. Sci. (China) 1992, 4 (4), 61-71.

(6) Liu, Guoguang, Study on the photorection of 1-(2chlorobenzoyl)-3-(4-chlorophenyl) urea. Doctoral Dissertation, Research Center for ECO-Environmental Sciences, Chinese Academy of Sciences, Beijing, China, 1990.

(7) Liu, Guoguang; Xu, Xiaobai. The preliminary study of the kinetics of photodecomposition of Benzamide, 2chloro-N-(((4-chlorophenyl)amino)carbonyl) in water. Huanjing Huaxue 1993, 12 (1), 47-52.

(8) Liu, Sufen; Jiang, Xiangning; Liu, Guoguang; Xu, Xiaobai. Investigation of DNA-2-chlorobenzamide adduct. Huanjing Huaxue 1997, 16 (4), 316-320.

(9) Riley, W. C.; J acobson, R. A. 1-(4-chlorophenyl)-3-(2,6difluorobenzoyl) urea (Difluorbenuron). Cryst. Struct. Commun. 1981, 10, 1341.

(10) Zhou, Qingxiang; Lu, Wenying; Liu, Guoguang; Xue, Xiuling. Study on the hydrolysis of 2-chlorobenzamide, J . Agric. Food Chem. 2000, 48, 2572-2575.

(11) Liu, Guoguang; Zhou, Qingxiang; Lu, Wenying. The formation of 2-chlorobenzamide upon hydrolysis of the benzoyl phenylurea. I nsecticide 1-(2-chlorobenzoyl)-3-(4chlorophenyl) urea in different water systems. J . Agric. Food Chem. 2001, 49, 1304-1308.

Received for review J une 1, 2000. Revised manuscript received February 9, 2001. Accepted F ebruary 12, 2001. This work was supported partly by the National Natural Science Foundation of China (29837180) and Basic Research XZ-951-209-02, RCEES-9906, CAS.

J F 000681H 